\title{
FXII regulates the formation of deep vein thrombosis via the PI3K/AKT signaling pathway in mice
}

\author{
YAN MENG, QIAN YIN, QIANG MA, HAO QIN, JUNBO ZHANG, \\ BO ZHANG, HONGGANG PANG and HONGYAN TIAN \\ Department of Peripheral Vascular Diseases, The First Affiliated Hospital of \\ Xi'an Jiaotong University, Xi'an, Shaanxi 710061, P.R. China
}

Received February 29, 2020; Accepted January 29, 2021

DOI: $10.3892 / \mathrm{ijmm} .2021 .4920$

\begin{abstract}
Deep vein thrombosis (DVT) is a common peripheral vascular disease, which may result in pulmonary embolism and is accompanied by endothelial injury. However, the pathogenesis of DVT remains unclear. Coagulation factor XII (FXII), as an important coagulation factor, has been reported to be closely associated with thrombosis. However, the association between FXII protein and DVT formation is not yet fully understood. The present study examined the effects of FXII protein on DVT formation and aimed to reveal the underlying mechanism. In the present study, histological characterization of the femoral vein tissue was examined by hematoxylin and eosin staining. The damage to the femoral vein tissue was examined by TUNEL assay. Superoxide dismutase (SOD) and malondialdehyde (MDA) concentrations were examined using ELISA. Tumor necrosis factor (TNF)- $\alpha$, interleukin (IL)-6, IL-8 and phosphoinositide 3-kinase (PI3K)/AKT signaling were determined by ELISA, immunohistochemical staining and western blot analysis. The results demonstrated that thrombosis, FXII protein, cell apoptosis and the SOD concentrations were decreased, while the MDA concentrations were increased in mice with DVT compared with the control or sham groups. TNF- $\alpha$, IL-6, IL-8 and PI3K/AKT signaling was also upregulated in the mice with DVT. Furthermore, the knockdown of FXII significantly upregulated the SOD concentrations and downregulated thrombosis and cell apoptosis, as well as the MDA concentrations in mice with DVT. The knockdown of FXII also significantly downregulated the protein expression of TNF- $\alpha$, IL- 6 and IL-8, and the activation of PI3K/AKT signaling. Additionally, LY294002 pre-treatment markedly downregulated thrombosis and cell apoptosis and the MDA
\end{abstract}

Correspondence to: Professor Hongyan Tian, Department of Peripheral Vascular Diseases, The First Affiliated Hospital of Xi'an Jiaotong University, 277 Yanta Road, Xi'an, Shaanxi 710061, P.R. China

E-mail: hongyantian417@126.com

Key words: deep vein thrombosis, coagulation factor XII, PI3K/AKT signaling, inflammatory response content, whereas it upregulated the SOD concentrations in mice with DVT. LY294002 pre-treatment also significantly downregulated the TNF- $\alpha$, IL- 6 and IL- 8 protein levels. Taken together, the present study demonstrates that FXII protein promotes DVT via the activation of PI3K/AKT signaling by inducing an inflammatory response. Targeting FXII protein may thus prove to be a potential approach for the treatment of DVT.

\section{Introduction}

Deep vein thrombosis (DVT) is a form of a blood clotting in the deep veins, which can occur in any part of the body, but typically occurs in the legs (1). DVT, as a common peripheral vascular disease, is often accompanied by endothelial injury and may develop into pulmonary embolism, which is related to mortality $(2,3)$. Additionally, $>20 \%$ of affected patients may develop post-thrombotic syndrome, which can seriously affect the quality of life of patients in the later stages of DVT (4). The incidence of DVT is 1 in 1,000 adults and increases with age $(5,6)$; there are 10 million diagnosed cases in China $(5,7)$. DVT is a complex event and the disease pathogenesis remains to be elucidated. Moreover, to date, thrombus-related damage to the vein wall cannot be effectively inhibited by pharmacological methods (8). Evidence has demonstrated that inflammatory markers, including the inflammatory cytokines, tumor necrosis factor (TNF)- $\alpha$, interleukin (IL)-6 and IL-8 (9) contributed to the formation of DVT. However, the underlying molecular mechanisms are not yet fully understood.

Coagulation factor XII (FXII), a type of serine protease zymogen, is a key coagulation factor and the initiating factor of the intrinsic coagulation pathway. It has been reported that FXII may activate coagulation pathway related-proteins via the factors XI and IX $(10,11)$. FXII has been reported to be involved in various physiological processes, including coagulation, fibrinolysis and angiogenesis. It has also been demonstrated that FXII protein may play an important role in regulating thrombosis (12). Furthermore, FXII-deficient animals may effectively prevent thrombus formation without impaired hemostasis (13-15). Additionally, FXII protein is closely associated with inflammatory disorders, including rheumatoid arthritis and colitis. FXII protein may promote the inflammatory response by upregulating the protein expression 
of TNF- $\alpha$, IL- 6 and IL- 8 in lungs affected by acute respiratory distress syndrome (16). The phosphoinositide 3-kinase (PI3K)/AKT signaling pathway is an important signaling pathway in the regulation of the inflammatory response. Of note, FXII protein may induce the activation of AKT signaling (17). These data indicate that FXII protein may play an important role in the formation of DVT. However, to the best of our knowledge, the effects of the FXII-mediated activation of the PI3K/AKT signaling pathway on the formation of DVT have not been reported to date.

The present study thus attempted to investigate the mechanisms of the FXII-mediated PI3K/AKT signaling pathway in the formation of DVT. A mouse model of DVT was used to assess whether FXII protein and the PI3K/AKT signaling pathway are involved in the regulation of the formation of DVT, and to further reveal the molecular mechanisms of the FXII-mediated activation of PI3K/AKT signaling in the formation of DVT. These findings may provide theoretical evidence and a potential approach with which to attenuate the formation of DVT.

\section{Materials and methods}

Drugs and antibodies. LY294002 (a PI3K inhibitor) was purchased from Sigma-Aldrich; Merck KGaA. Anti-PI3K (\#AF5121) and anti-phosphorylated (p)-PI3K (\#AF3241) antibodies were purchased from Affinity Biosciences. Anti-factor XII (\#12551-1-AP) was purchased from ProteinTech Group, Inc. Anti-AKT (\#4685), anti-p-AKT (\#4060) and anti-GAPDH (\#2118) antibodies and HRP-conjugated secondary antibodies were purchased from Cell Signaling Technology, Inc.

Animal experiments. A total of 66 7-week-old male C57BL/6 mice (weighing 20-21 g) were purchased from the Experimental Animal Center of Xi'an Jiaotong University. All mice were randomly assigned to the following groups: The control group (A), the sham-operated group (B) and the model group (C), with 6 mice in each group. All mice were kept in a specific pathogen-free facility for 1 week of adaptive feeding. The mouse model of DVT was established as previously described (18). The mice were anesthetized using an animal isoflurane anesthesia machine (R520, RWD Life Science, anesthesia was induced by $4 \%$ isoflurane and maintained by $1.5 \%$ isoflurane) and fixed on an operating table. The abdomen of the mice was opened in the middle of the abdominal white line, and the small bowel and other organs in the abdominal cavity were exteriorized onto a piece of sterile gauze pre-soaked with normal saline. After exposing the inferior vena cava (IVC) and its branches, the IVC was carefully separated and all the visible branches of the IVC were ligated. Once the proximal and distal IVC were clamped using a vascular clamp for $30 \mathrm{sec}$, the IVC was passed through the rear with a 6-0 suture. The IVC was ligated using a 4-0 suture, and the 6-0 suture was then rapidly drawn out. After confirming that the respiratory circulation of the mice was stable, the abdominal incision of the mice was closed layer by layer and the mice were fed normally. The mice in the model groups also were randomly assigned to 4 subgroups as follows: C, model group; D, model group transfected with adenovirus vector pAd-pG2.1; E, model group transfected with adenovirus vector pAd-pG2.1-small interfering RNA (siRNA) FXII; and
F, model group treated with LY294002 (50 mg/kg): The mice were injected with treated with LY294002 (50 mg/kg) through the tail vein (twice, $0.5 \mathrm{~h}$ prior to the establishment of the DVT model and $24 \mathrm{~h}$ after the establishment of the DVT model). In the present study, 18 mice were used for the experiments shown in Figs. 1-3 (3 groups, 6 mice in each group), 30 mice were used for the experiments shown in Figs. 4-6 (5 groups, 6 mice in each group) and 18 mice were used for the experiments shown in Figs. 7 and 8 (3 groups, 6 mice in each group). The mice were intraperitoneally injected with $1 \mathrm{ml} 3 \%$ pentobarbital sodium $(30 \mathrm{mg} / \mathrm{kg})$ and the femoral vein tissue of mice was excised at $48 \mathrm{~h}$ following the establishment of the DVT model. At the end of the experiment ( $48 \mathrm{~h}$ following the establishment of the DVT model), the mice underwent euthanasia via cervical dislocation to confirm death. The experimental procedures and protocols were reviewed and approved by the Animal Investigation Ethics Committee of the First Affiliated Hospital of Xi'an Jiaotong University and were performed in accordance with the Guidelines for the Care and Use of Laboratory Animals from the National Institutes of Health, China.

Humane endpoints. The humane endpoints of the animal experiments were performed in accordance with the Association of Primate Veterinarians' Humane Endpoint Guidelines for Nonhuman Primates in Biomedical Research, 2020 and Institutional Animal Care and Use Committee Guidebook (http://grants.nih.gov/grants/olaw/GuideBook. pdf). Humane endpoints were at $48 \mathrm{~h}$ after establishment of DVT model. However, humane endpoints involved immediate intervention under the following conditions: i) The body weight of the mice decreased $15-20 \%$ following the establishment of the DVT model; ii) the mice lost complete interest in eating for $24 \mathrm{~h}$ following the establishment of the DVT model; iii) the mice could not drink and eat by themselves; iv) the mice could not stand for $24 \mathrm{~h}$ following the establishment of the DVT model; v) abnormal central nervous responses (such as convulsion and paralysis) and inability to control pain in mice following the establishment of the DVT model; vi) other abnormal phenomena in mice, such as persistent self-mutilation, persistent hypothermia following the establishment of the DVT model.

Histological analysis. The femoral vein injury was evaluated by hematoxylin and eosin (H\&E) staining. To assess the histological characterization of the femoral vein tissue, the femoral vein tissue was excised from the mice and fixed with $4 \%$ paraformaldehyde at $48 \mathrm{~h}$ after surgery. The femoral vein tissue was dehydrated in graded concentrations of ethanol and then embedded in paraffin. The femoral vein tissue was cut into sections at a thickness of 5- $\mu \mathrm{m}$. Following dewaxing and rehydration, the slices were stained with H\&E by using a Hematoxylin and Eosin Staining kit (Beyotime Institute of Biotechnology) according to the manufacturer's instructions. The final stained sections were photographed using an BX-50 Olympus light microscope (Olympus Corporation) equipped with a DP22 camera at x400 magnification.

Determination of inflammatory cytokine levels. The femoral vein tissue of the mice was homogenized, and supernatant samples were collected and stored at $-80^{\circ} \mathrm{C}$ prior to use. The 
mice were anesthetized using an animal isoflurane anesthesia machine (R520, RWD Life Science, anesthesia was induced by $4 \%$ isoflurane and maintained by $1.5 \%$ isoflurane). A total of $200 \mu \mathrm{l}$ each of mouse plasma was also obtained by mouse retro-orbital sinus blood collection and stored at $-80^{\circ} \mathrm{C}$ prior to use. The concentrations of IL- 8 , and the cytokine levels of IL- 6 and TNF- $\alpha$ in femoral vein tissue or plasma were examined using corresponding specific ELISA kits (Elabscience, Inc.) according to the manufacturer's instructions. Each sample was tested in triplicate. The absorbance at a wavelength of $450 \mathrm{~nm}$ was examined using a Multiskan MK3 microplate reader (Thermo Fisher Scientific, Inc.).

Determination of malondialdehyde (MDA) and superoxide dismutase (SOD) levels. The femoral vein tissue of mice was homogenized on ice in sterile saline by using TissueLyser-24 tissue homogenizer (Shanghai Jingxin Industrial Development Co., Ltd.), and supernatant samples were collected. The concentration of MDA and SOD in the femoral vein tissue was examined using corresponding specific assay kits (Nanjing Jiancheng Bioengineering Institute) according to the manufacturer's instructions. The MDA and SOD samples were tested in triplicate. The absorbance at wavelengths of $532 \mathrm{~nm}$ (MDA) and $450 \mathrm{~nm}$ (SOD) was examined using a Multiskan MK3 microplate reader (Thermo Fisher Scientific, Inc.).

TUNEL assay and immunohistochemical staining. The femoral vein tissue was dehydrated in graded concentrations of ethanol and embedded in paraffin. The femoral vein tissue was cut into sections with a thickness of $4 \mu \mathrm{m}$. Following dewaxing and rehydration, cell apoptosis of the femoral vein tissue was examined using a TUNEL Apoptosis Detection kit (Alexa Fluor 640; Shanghai Yeasen Biotechnology Co., Ltd.) according to the manufacturer's instructions. The femoral vein tissue was stained with $2 \mu \mathrm{g} / \mathrm{ml}$ DAPI (Beyotime Institute of Biotechnology) for $5 \mathrm{~min}$ at $25^{\circ} \mathrm{C}$ in a dark room. Sections of the femoral vein tissue were also incubated with anti-PI3K (1:100), anti-p-PI3K (1:100), anti-AKT (1:100), anti-p-AKT (1:100) and anti-factor XII (1:100) antibodies overnight at $4{ }^{\circ} \mathrm{C}$, followed by incubation with HRP-conjugated secondary antibodies (1:50) for $45 \mathrm{~min}$ at $37^{\circ} \mathrm{C}$. After the final wash, the sections were observed using a Dako REAL EnVision Detection system.

Construction of adenoviral vectors encoding siRNA FXII. Antisense FXII cDNA was constructed according to the FXII sequence (GCAAGAGTCTGTCTTCGAT) was constructed. Antisense FXII cDNA was inserted into the plasmids pG2.1 (Biofavor Biotechnology Services Co. Ltd.) using 2 cDNA primers (5'-CACCGCAAGAGTCTGTCTTCGATTTCAAGA CGATCGAAGACAGACTCTTGCTTTTTTG-3' and 5'-AGC TCAAAAAAGCAAGAGTCTGTCTTCGATCGTCTTGAAA TCGAAGACAGACTCTTGC-3'). Briefly, antisense FXII cDNA was obtained from 2 primers annealed at $94^{\circ} \mathrm{C}$ and cooled to room temperature. pG2.1 plasmid was digested with $B s a \mathrm{I}$ and were ligated with antisense FXII cDNA at $22^{\circ} \mathrm{C}$ in a water bath overnight. The entire pG2.1-FXII siRNA was sub-cloned into the adenoviral vector, pAd/PL-DEST (Invitrogen; Thermo Fisher Scientific, Inc.) by Gateway LR Clonase ${ }^{\mathrm{TM}}$ II(Invitrogen; Thermo Fisher Scientific, Inc.) according to the manufacturer's instructions. Recombinant adenovirus (pAd-pG2.1-siRNA FXII) was obtained from 293 cells (Procell Co. Ltd.). Following 1 week of adaptive feeding, the mice in the model groups were injected with $1 \times 10^{8}$ plaque forming units per mouse.

Western blot analysis. The femoral vein tissues were homogenized using RIPA lysis buffer (Beyotime Institute of Biotechnology) with $1 \mathrm{mM}$ PMSF on ice for $30 \mathrm{~min}$. Following centrifugation at $12,000 \mathrm{x}$ g for $10 \mathrm{~min}$ at $4^{\circ} \mathrm{C}$, the supernatants were collected. The protein concentration was determined using a BCA Protein Test kit (Beyotime Institute of Biotechnology). Total protein $(20 \mu \mathrm{g} /$ well) were separated via $10 \%$ SDS-PAGE and transferred onto PVDF membranes (EMD Millipore). Membranes were blocked with $5 \%$ non-fat milk at $25^{\circ} \mathrm{C}$ for $2 \mathrm{~h}$ and incubated with primary antibodies against PI3K (1:1,000), p-PI3K (1:1,000), AKT (1:1,000), p-AKT (1:1,000) and GAPDH $(1: 2,000)$ at $4^{\circ} \mathrm{C}$ overnight. Subsequently, membranes were incubated with HRP-conjugated goat anti-rabbit secondary antibody $(1: 2,000)$ at $25^{\circ} \mathrm{C}$ for $2 \mathrm{~h}$. Protein bands were visualized using enhanced chemiluminescence detection reagent (Thermo Fisher Scientific, Inc.). Densitometric analysis was performed using ImageJ $1.38 \mathrm{X}$ software (National Institutes of Health).

Statistical analysis. GraphPad Prism 7 software (GraphPad Software, Inc.) was used to perform statistical analysis. All experiments were performed at least in triplicate and data are expressed as the mean \pm SD. Different variables between the 2 groups were analyzed using a Student's t-test and different variables between three or more groups were analyzed using one-way ANOVA followed by the Tukey's post-hoc tests. $\mathrm{P}<0.05$ was considered to indicate a statistically significant difference.

\section{Results}

Upregulation of FXII protein in the femoral vein tissue of mice with DVT. To assess FXII protein expression in the femoral vein tissue of mice, a mouse model of DVT was established and the histological characterization of the femoral vein tissue was performed by H\&E staining. As shown in Fig. 1A, thrombosis was significantly induced in the femoral vein tissue of the model group compared with the control or sham groups. Femoral vein tissue damage was examined by TUNEL assay, As shown in Fig. 1B, the cell apoptotic rate in the femoral vein tissue was significantly increased in the DVT model. SOD, a member of metalloproteinases, is a major free radical scavenger which significantly reduces free radical damage to the body and protects tissues from injury. MDA is a type of unsaturated fatty acid which can damage the biofilm and reflect the extent of lipid peroxidation and tissue injury (19-21). Thus, the SOD and MDA content plays an important role in vein thrombosis. Hence, in the present study, the SOD and MDA concentrations in the femoral vein tissue were measured using ELISA. The results revealed that the SOD concentrations were decreased, while the MDA concentrations were increased in the femoral vein tissue of the model group (Fig. 1C and D). Additionally, FXII protein expression was found to be upregulated in the femoral vein tissue of the model group, as shown by western blot analysis and immunohistochemical staining (Fig. 1E-G). These data thus indicated that FXII protein may be associated with the formation of DVT. 


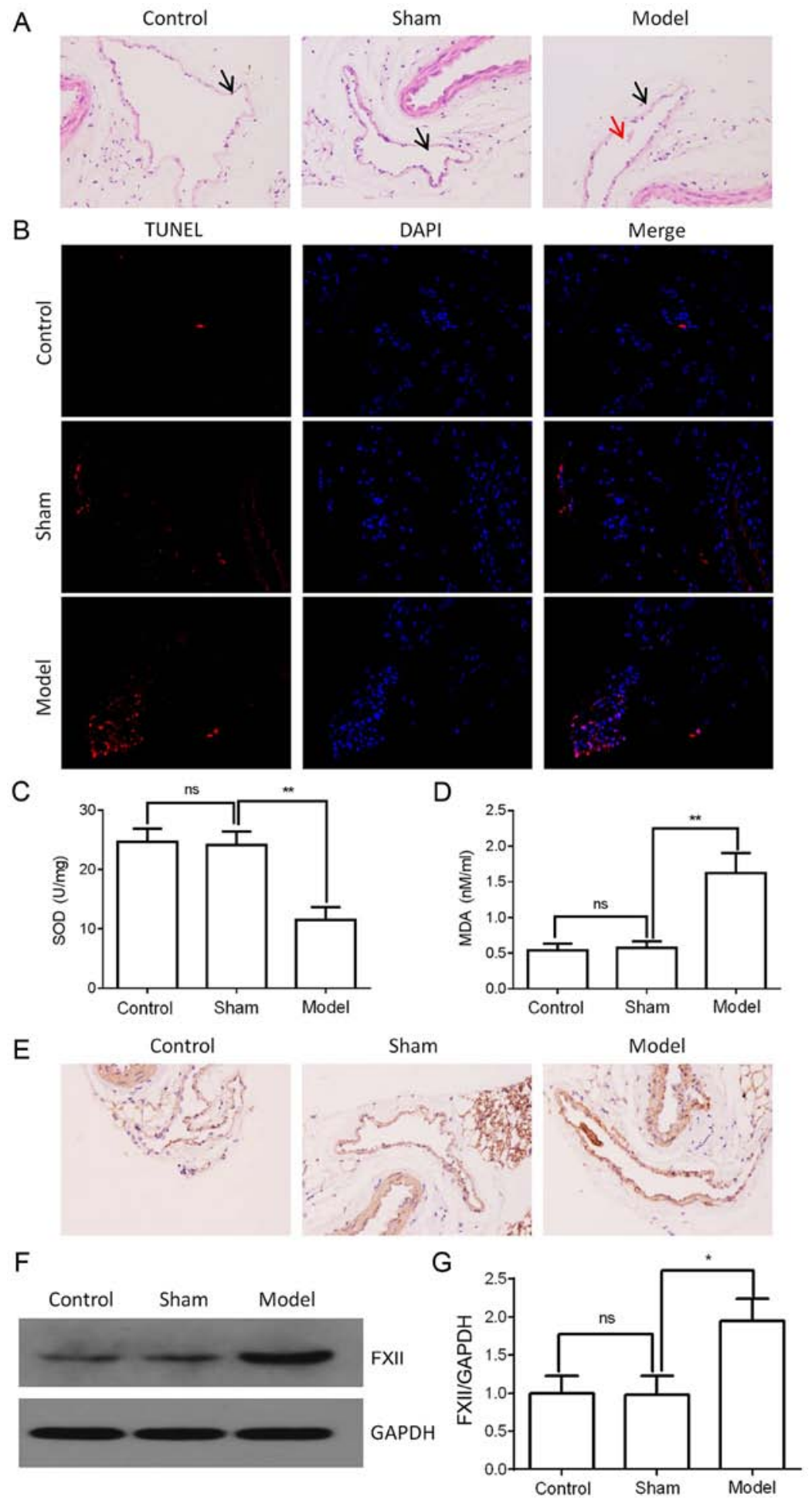

Figure 1. FXII protein expression in the femoral vein tissue of mice with DVT. (A) Thrombosis in the femoral vein tissue of different treatment groups ( $\mathrm{n}=6$ mice in each group) was examined by H\&E staining at $48 \mathrm{~h}$ after surgery (black arrows indicate the femoral vein tissue; red arrows indicate thrombosis). (B) Cell apoptosis of the femoral vein tissue in mice was examined by TUNEL assay. (C and D) SOD and MDA concentrations in the femoral vein tissue of mice were examined using ELISA. (E) FXII protein expression was examined by immunohistochemical staining. (F) FXII protein expression was examined by western blot analysis. GAPDH was used as the internal control. (G) Western blot analysis quantification of FXII protein expression. ${ }^{*} \mathrm{P}<0.05$ and ${ }^{* *} \mathrm{P}<0.01$; ns, not significant. FXII, coagulation factor XII; DVT, deep vein thrombosis; SOD, superoxide dismutase; MDA, malondialdehyde; H\&E, hematoxylin and eosin.

Upregulation of inflammatory cytokines in the femoral vein tissue and plasma of mice with DVT. The expression of inflammatory cytokines in the femoral vein tissue of mice was then investigated. The protein expression levels of TNF- $\alpha$, IL-6 and IL-8 in the femoral vein tissue and plasma of mice were examined using ELISA. Compared with the control or sham groups, the protein expression levels of TNF- $\alpha$, IL-6 and IL-8 were significantly increased in the femoral vein tissue of the model mice (Fig. 2A, C and E) and plasma of the model mice (Fig. 2B, D and F). These data suggested that inflammatory cytokines TNF- $\alpha$, IL- 6 and IL- 8 might be involved in DVT formation. 
A

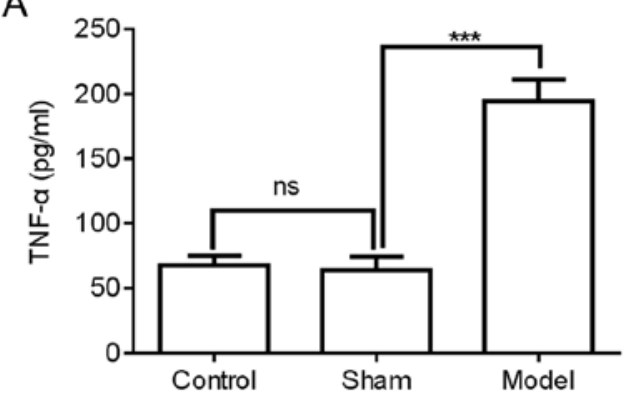

C

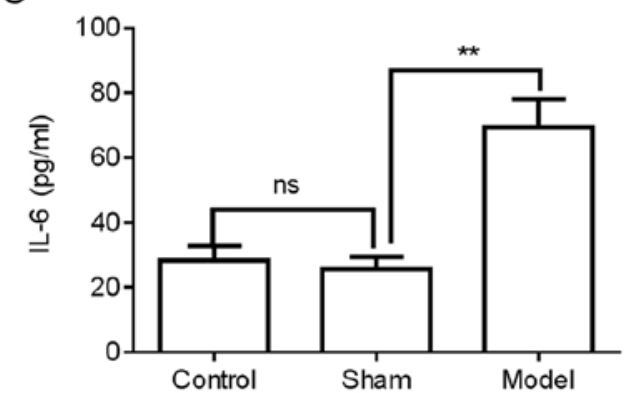

E

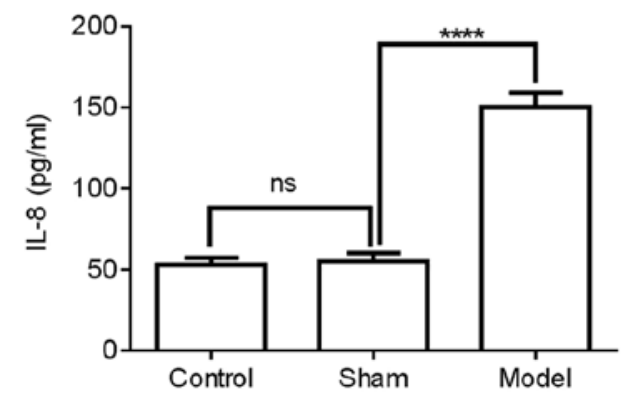

B

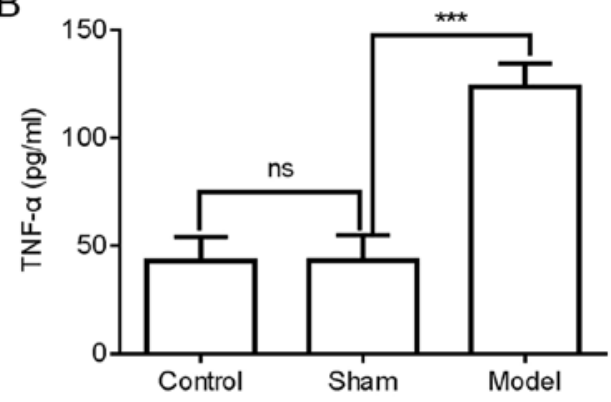

D

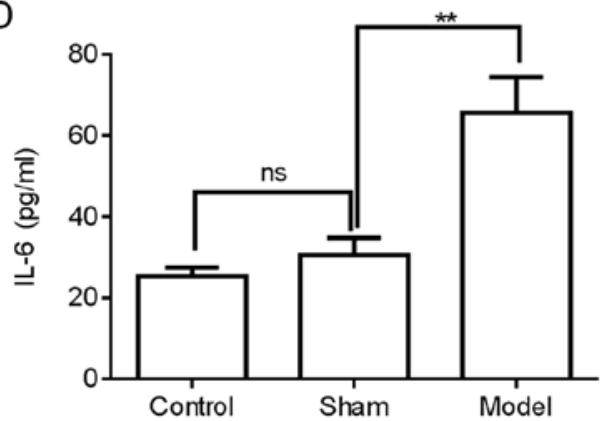

$\mathrm{F}$

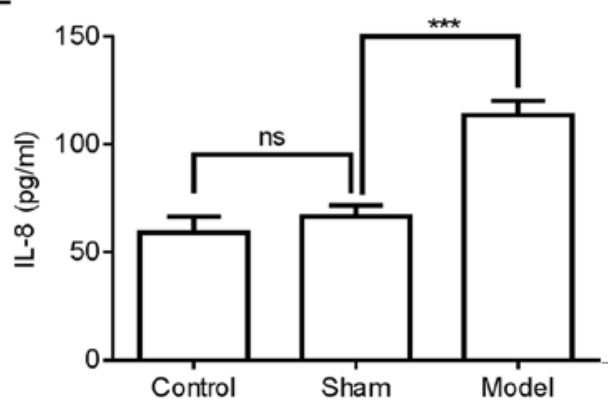

Figure 2. Expression of TNF- $\alpha$, IL-6 and IL- 8 protein in the femoral vein tissue and plasma of mice with DVT. (A, C and E) The levels of TNF- $\alpha$, IL- 6 and IL- 8 in the femoral vein tissue of different treatment groups ( $\mathrm{n}=6$ mice in each group) were detected using ELISA. (B, D and F) The levels of TNF- $\alpha$, IL- 6 and IL-8 in the plasma of mice in the different treatment groups ( $\mathrm{n}=6$ mice in each group) were detected using ELISA. ${ }^{* *} \mathrm{P}<0.01,{ }^{* * *} \mathrm{P}<0.001$ and ${ }^{* * * *} \mathrm{P}<0.0001 ; \mathrm{ns}, \mathrm{not}$ significant. DVT, deep vein thrombosis.

PI3K/AKT signaling is activated in the femoral vein tissue of mice with DVT. The activation of the PI3K/AKT signaling pathway was then determined. The levels of PI3K, p-PI3K, AKT and p-AKT were examined by western blot analysis and immunohistochemical staining. As shown in Fig. 3A and B, the protein expression of PI3K and AKT was not markedly altered in the femoral vein tissue of the model group compared with the control or sham groups. However, the p-PI3K and p-AKT levels were significantly upregulated in the femoral vein tissue of the model group (Fig. 3A-D). These results suggested that $\mathrm{PI} 3 \mathrm{~K} / \mathrm{AKT}$ signaling may be involved in the regulation of DVT formation.

FXII protein promotes the formation of DVT by activating PI3K/AKT signaling and upregulating inflammatory cytokine levels. Based on the aforementioned results, it was then determined whether FXII is involved in regulating the formation of DVT. FXII knockdown was achieved using adenoviral particle pAd-pG2.1-siRNA FXII in mice with DVT. The transfection efficiency of pAd-pG2.1-siRNA FXII in mice was first assayed by detecting the protein expression level of FXII following transfection with pAd-pG2.1-siRNA
FXII in the femoral vein tissue. The results revealed that FXII protein expression was downregulated in the femoral vein tissue of the pAd-pG2.1-siRNA FXII model group compared with model or pAd-pG2.1-siRNA NC model groups (Fig. 4A and B). H\&E staining revealed that pAd-pG2.1-siRNA FXII transduction significantly attenuated thrombosis compared with pAd-pG2.1-NC transduction in the femoral vein tissue of mice with DVT (Fig. 4C). Femoral vein tissue damage was then examined by TUNEL assay. As shown in Fig. 4D, FXII knockdown significantly decreased cell apoptosis in the femoral vein tissue of mice with DVT. FXII knockdown also significantly downregulated the MDA concentrations and upregulated the SOD concentrations in the femoral vein tissue of mice with DVT (Fig. 4E and F). Furthermore, ELISA was performed to assess the effects of FXII knockdown on inflammatory cytokine expression. As shown in Fig. 5A, C and E, FXII knockdown significantly downregulated the expression TNF- $\alpha$, IL- 6 and IL- 8 protein in the femoral vein tissue and plasma of mice with DVT. As shown in Fig. 5B, D and F, FXII knockdown significantly downregulated the protein expression of TNF- $\alpha$, IL- 6 and IL- 8 in the plasma of mice 
A

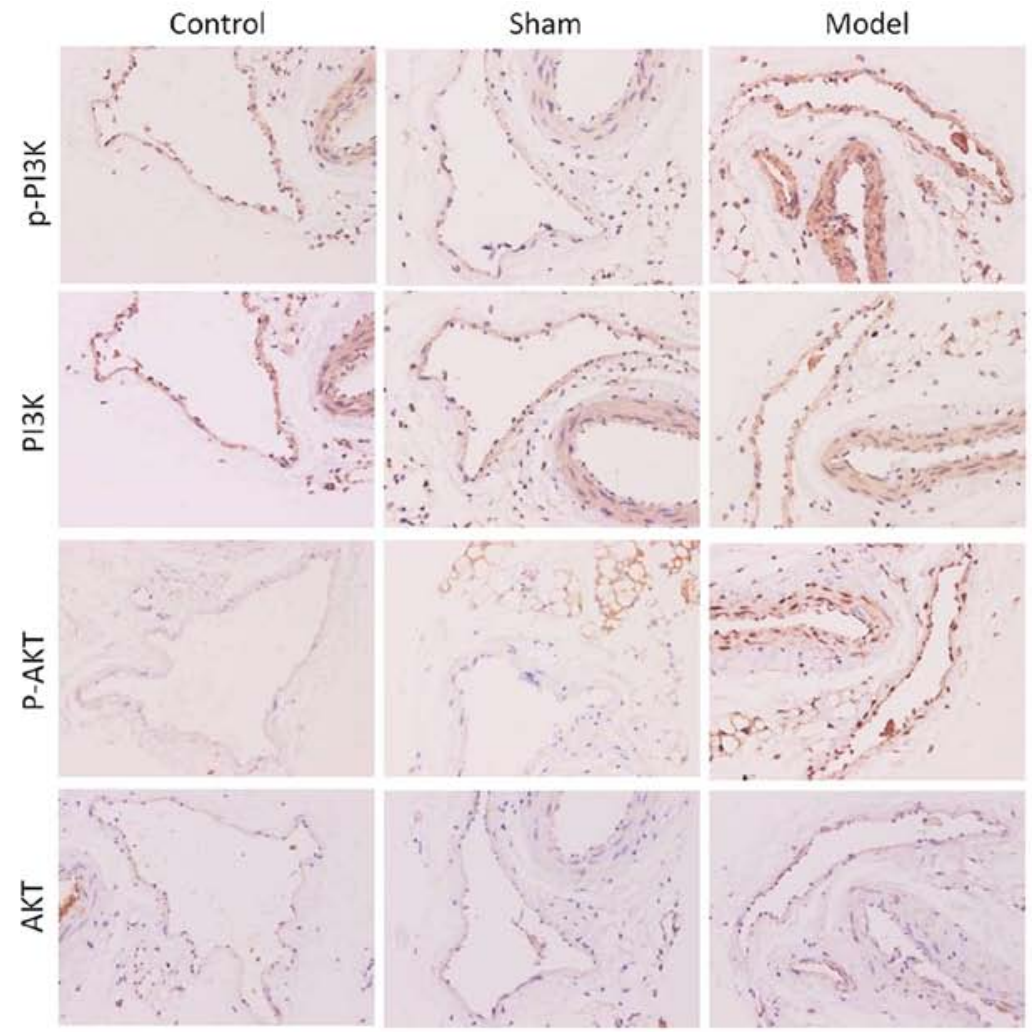

B

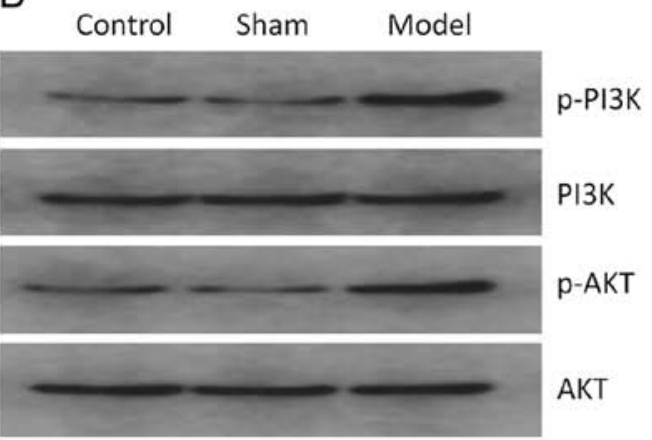

C
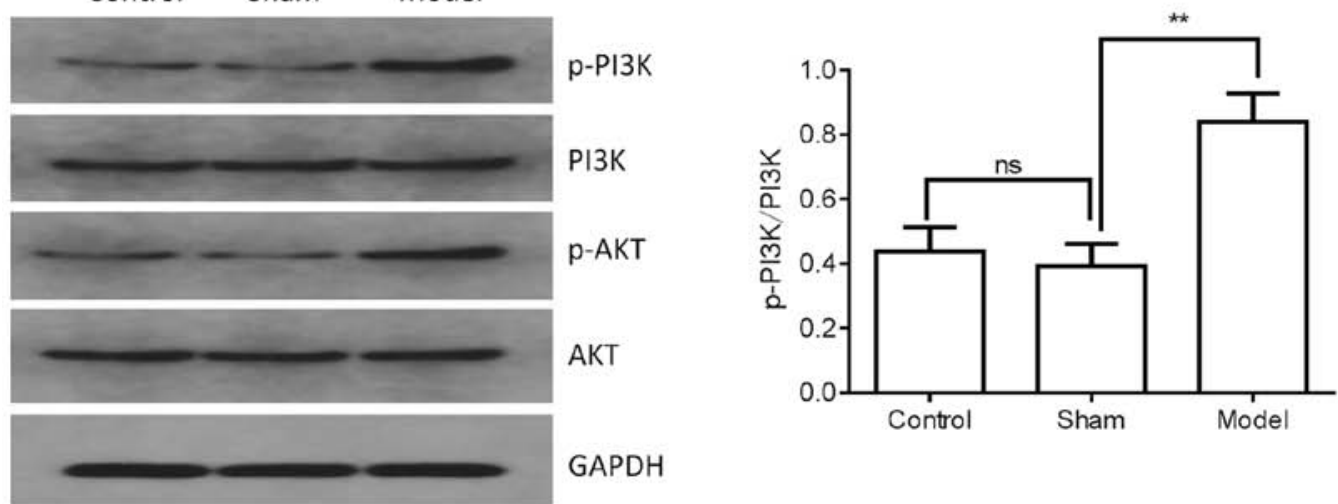

D

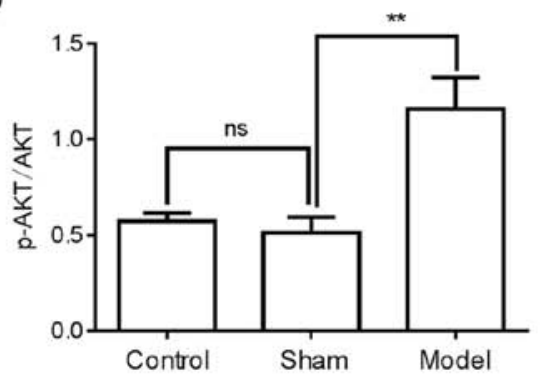

Figure 3. Activation of PI3K/AKT signaling in the femoral vein tissue of mice with DVT. (A and B) The levels of PI3K, p-PI3K, AKT and p-AKT in the femoral vein tissue of different treatment groups ( $\mathrm{n}=6$ mice in each group) were determined by western blot analysis and immunohistochemical staining. (C and D) Western blot analysis quantification of PI3K, p-PI3K, AKT and p-AKT levels. ${ }^{* *}$ P $<0.01$; ns, not significant. DVT, deep vein thrombosis; p, phosphorylated.

with DVT. Additionally, the effects of FXII knockdown on the PI3K/AKT signaling pathway were assessed by western blot analysis and immunohistochemical staining. As shown in Fig. 6A and B, FXII knockdown did not markedly alter PI3K and AKT protein expression. However, the p-PI3K and p-AKT levels significantly decreased following FXII knockdown in the femoral vein tissue of mice with DVT (Fig. 6A-D). Taken together, the data indicated that FXII induced DVT formation by regulating PI3K/AKT signaling and inflammatory cytokines. 


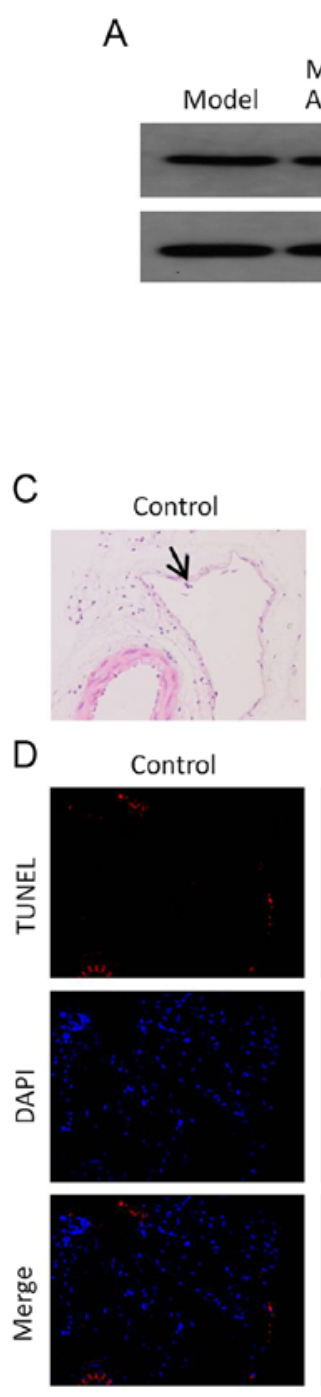

E

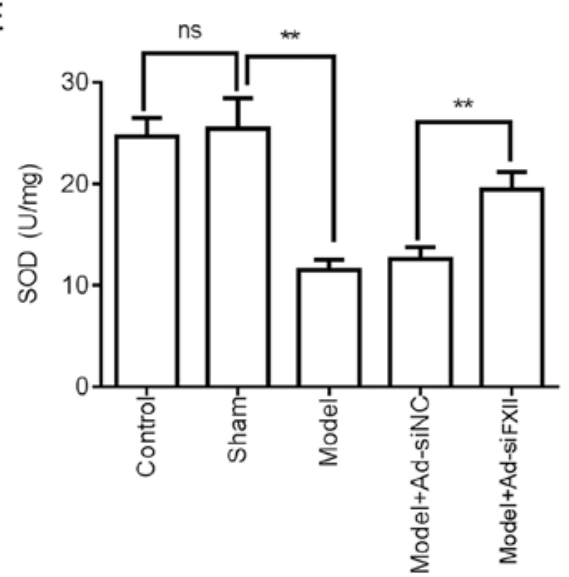

Sham
B
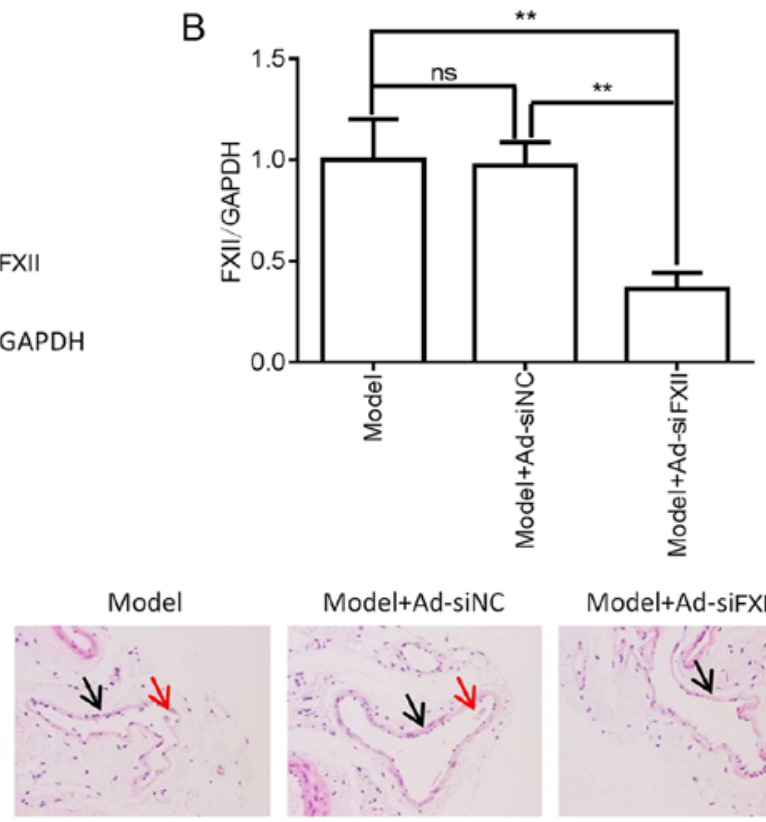

Model+Ad-siNC

Model+Ad-siFXII

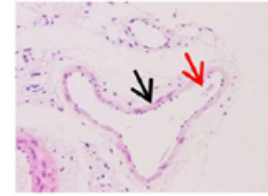

Model+Ad-siNC
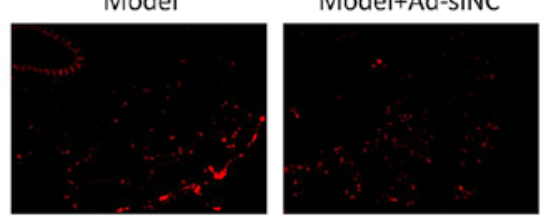

Model+Ad-siFXII
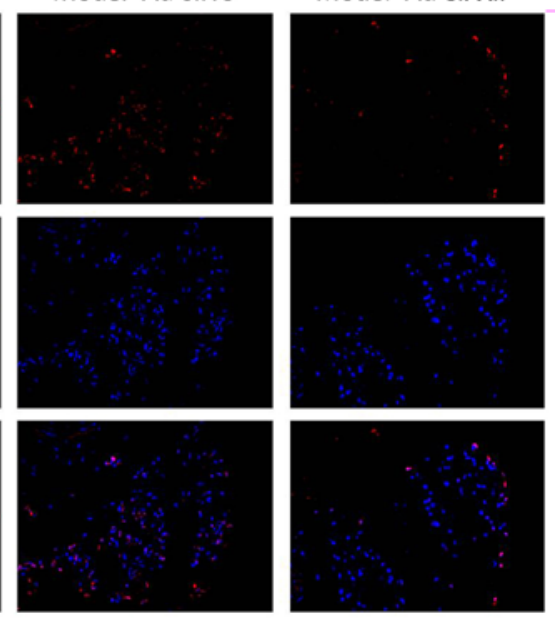

F

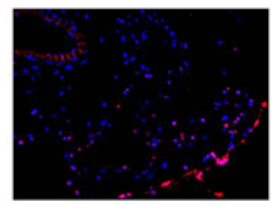

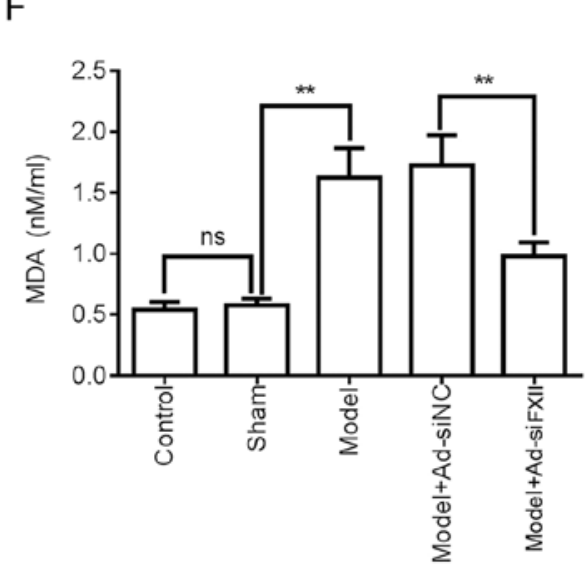

Figure 4. Effects of FXII protein on the thrombosis of femoral vein tissue of mice with DVT. FXII protein was knocked down by transfection with pAd-pG2.1-siRNA FXII (1x10 $10^{8}$ fu/mice). (A and B) Western blot analysis quantification of the expression level of FXII protein in the femoral vein tissue of mice. (C) Thrombosis in the femoral vein tissue of different treatment groups ( $\mathrm{n}=6$ mice in each group) was examined by H\&E staining (black arrows indicate the femoral vein tissue; red arrows indicate thrombosis). (D) Cell apoptosis of the femoral vein tissue in mice was examined by TUNEL assay. (E and F) SOD and MDA concentrations in the femoral vein tissue of mice were examined by ELISA. ${ }^{* *} \mathrm{P}<0.01$; ns, not significant. FXII, coagulation factor XII; DVT, deep vein thrombosis; siRNA, small interfering RNA; pfu, plaque-forming units; H\&E, hematoxylin and eosin.

PI3K/AKT signaling promotes DVT formation by upregulating inflammatory cytokine levels. The present study also investigated whether the activation of PI3K/AKT signaling induces DVT formation. The results of H\&E staining 
A

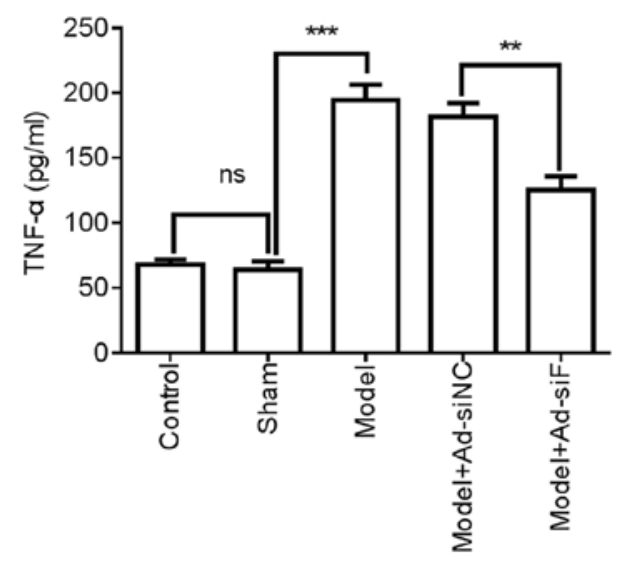

C

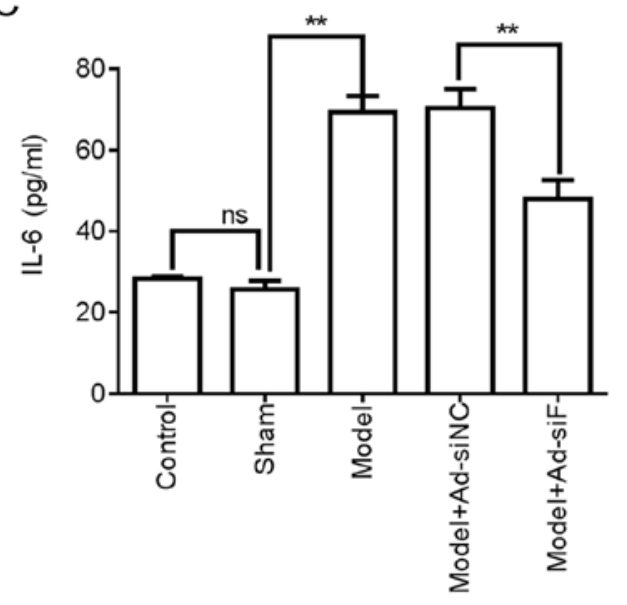

E

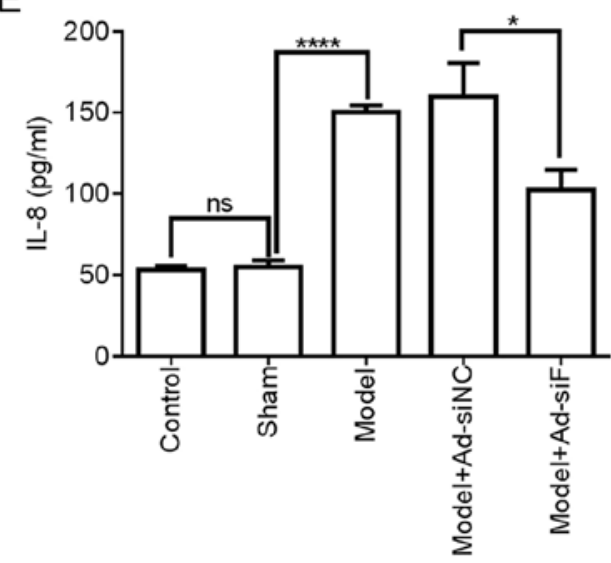

B

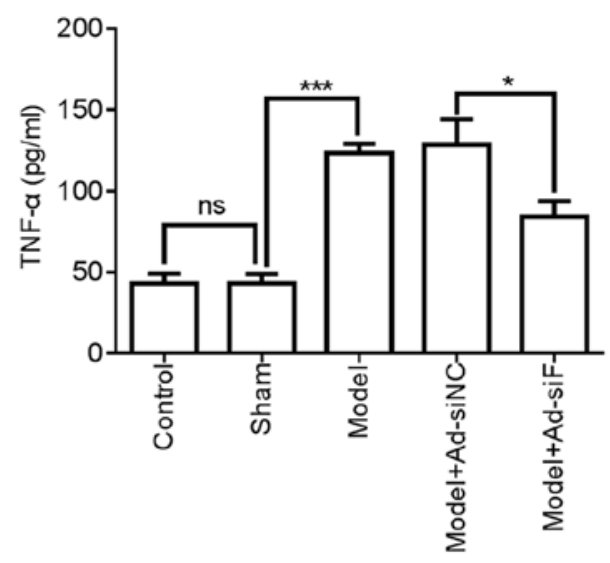

D

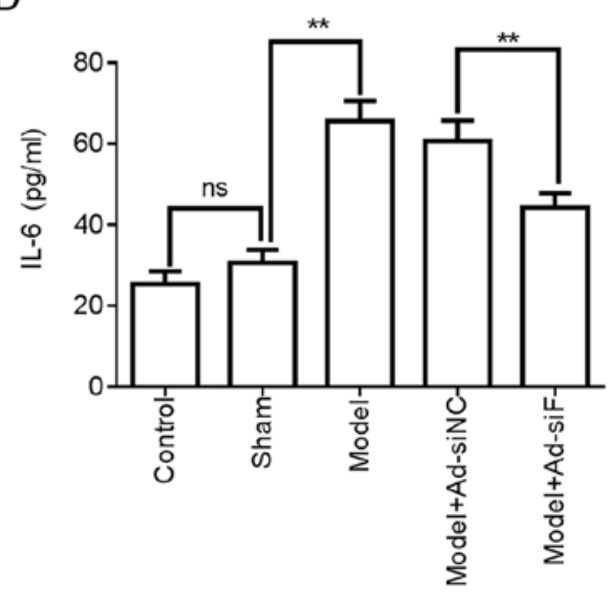

$\mathrm{F}$

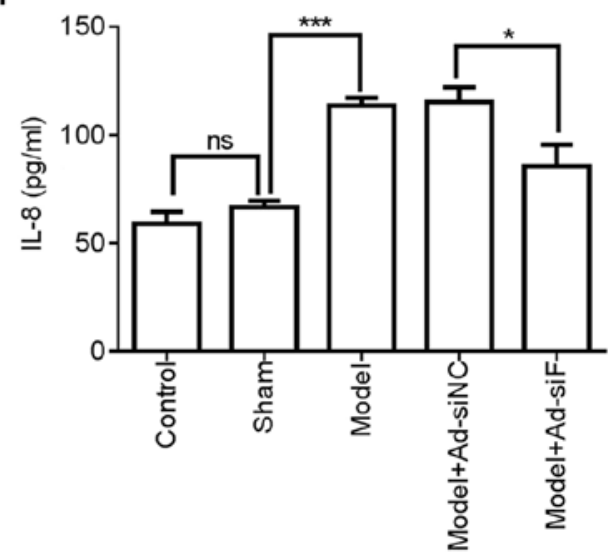

Figure 5. Effects of FXII protein on TNF- $\alpha$, IL-6 and IL-8 protein in the femoral vein tissue and plasma of mice with DVT. FXII protein was knocked down by transfection with pAd-pG2.1-siRNA FXII ( $1 \times 10^{8}$ pfu/mice). (A, C and E) The levels of TNF- $\alpha$, IL- 6 and IL-8 in the femoral vein tissue of different treatment groups ( $\mathrm{n}=6$ mice in each group) were detected using ELISA. (B, D, and F) The levels of TNF- $\alpha$, IL- 6 and IL- 8 in the plasma of mice in the different treatment groups ( $\mathrm{n}=6$ mice in each group) were detected using ELISA. ${ }^{*} \mathrm{P}<0.05,{ }^{* *} \mathrm{P}<0.01,{ }^{* * * *} \mathrm{P}<0.001$ and ${ }^{* * * * *} \mathrm{P}<0.0001$; ns, not significant. FXII, coagulation factor XII; DVT, deep vein thrombosis; siRNA, small interfering RNA; pfu, plaque-forming units.

demonstrated that pre-treatment with LY294002, a PI3K inhibitor, markedly decreased thrombosis in the femoral vein tissue of mice with DVT (Fig. 7A). Furthermore, femoral vein tissue damage was assessed by TUNEL assay and ELISA. As shown in Fig. 7B-D, LY294002 pre-treatment markedly decreased cell apoptosis and the MDA concentration, and increased the SOD concentration in the femoral vein tissue of mice with DVT. In addition, LY294002 pre-treatment significantly attenuated the protein expression of TNF- $\alpha$, IL- 6 and IL- 8 in the femoral vein tissue of mice with DVT (Fig. 8A, C and E) and plasma of mice with DVT (Fig. 8B, D and F). These results suggested that PI3K/AKT signaling induced DVT formation by regulating inflammatory cytokine levels.

\section{Discussion}

The present study found that thrombosis and damage significantly increased in the femoral vein tissue of mice with DVT 

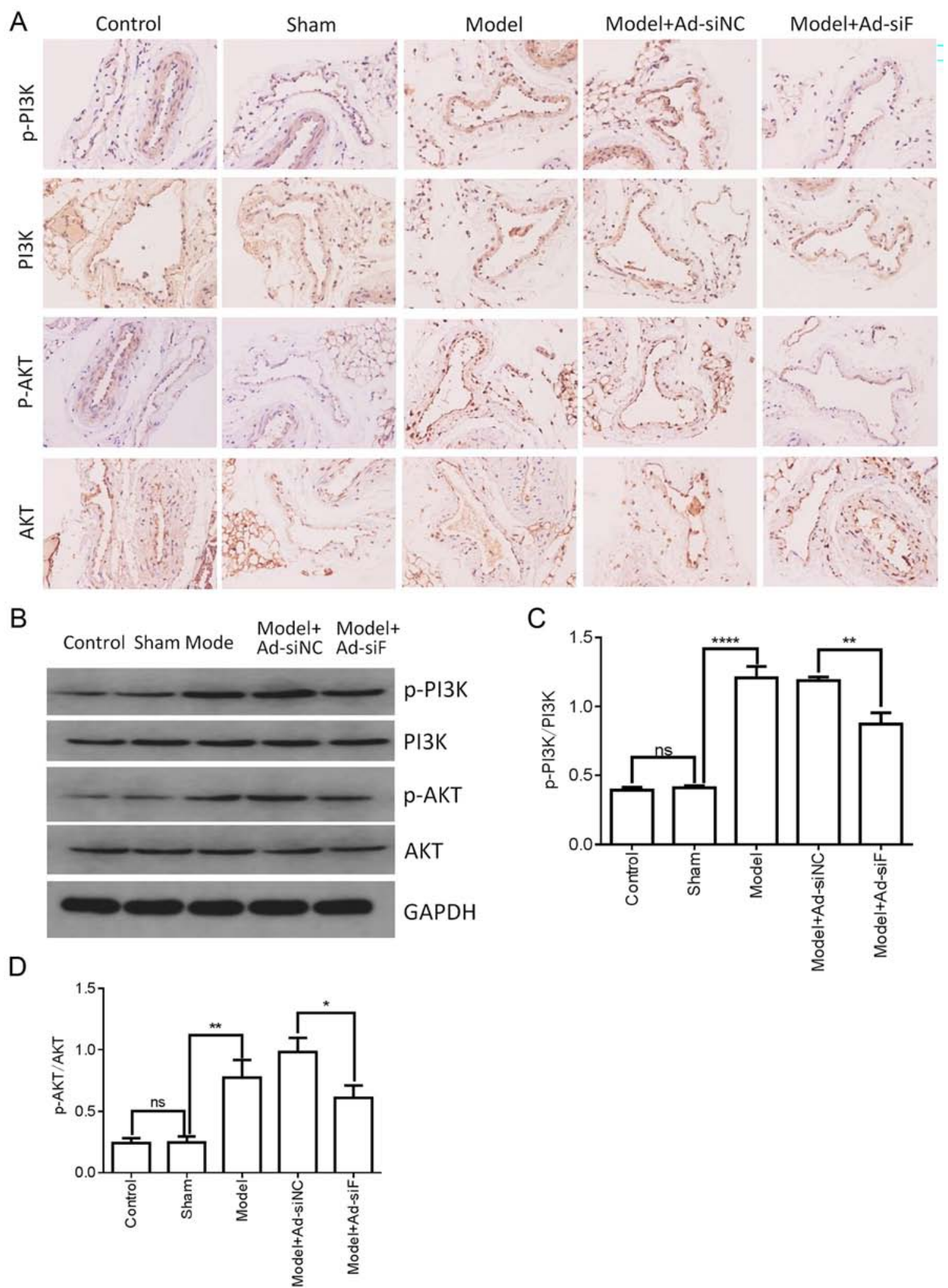

Figure 6. Effects of FXII protein on the activation of PI3K/AKT signaling in the femoral vein tissue of DVT mice. FXII protein was knocked down by transfection with pAd-pG2.1-siRNA FXII (11 $10^{8}$ pfu/mice). (A and B) The levels of PI3K, p-PI3K, AKT and p-AKT in the femoral vein tissue of different treatment groups ( $\mathrm{n}=6$ mice in each group) were determined by western blotting and immunohistochemical staining. (C and $\mathrm{D})$ Western blot analysis quantification of PI3K, p-PI3K, AKT and p-AKT levels. "P<0.05, ${ }^{* *} \mathrm{P}<0.01$ and ${ }^{* * * * *} \mathrm{P}<0.0001$; ns, not significant. FXII, coagulation factor XII; DVT, deep vein thrombosis; siRNA, small interfering RNA; pfu, plaque-forming units; p, phosphorylated.

compared with the control or sham groups. It was also found that FXII protein, PI3K/AKT signaling and the protein levels of the inflammatory cytokines, TNF- $\alpha$, IL-6 and IL-8, were upregulated in the femoral vein tissue of mice with DVT.
Mechanistic analyses further demonstrated that the effects of FXII protein on thrombosis and femoral vein tissue damage in mice with DVT was associated with PI3K/AKT signaling and the inflammatory cytokines, TNF- $\alpha$, IL-6 and IL-8. FXII 
A

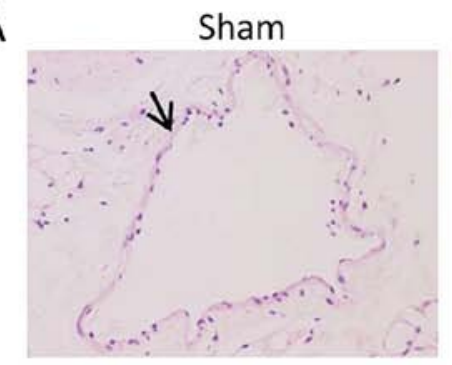

B
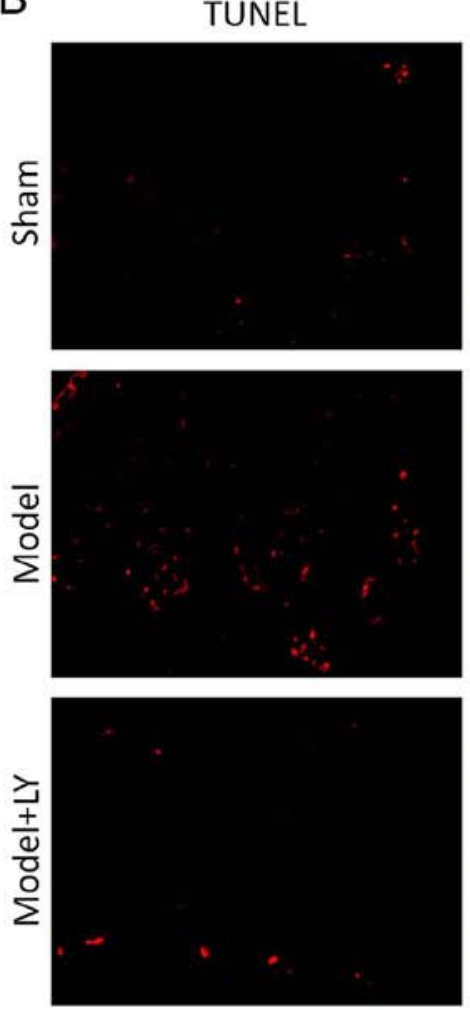

C

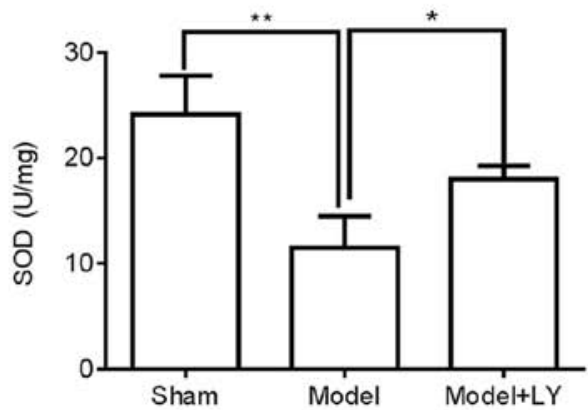

Model

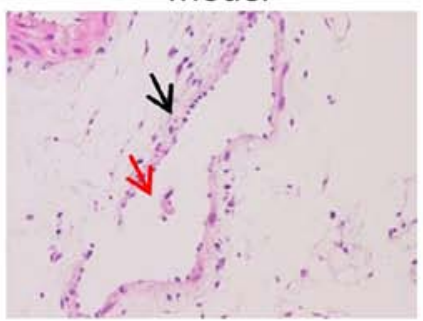

DAPI
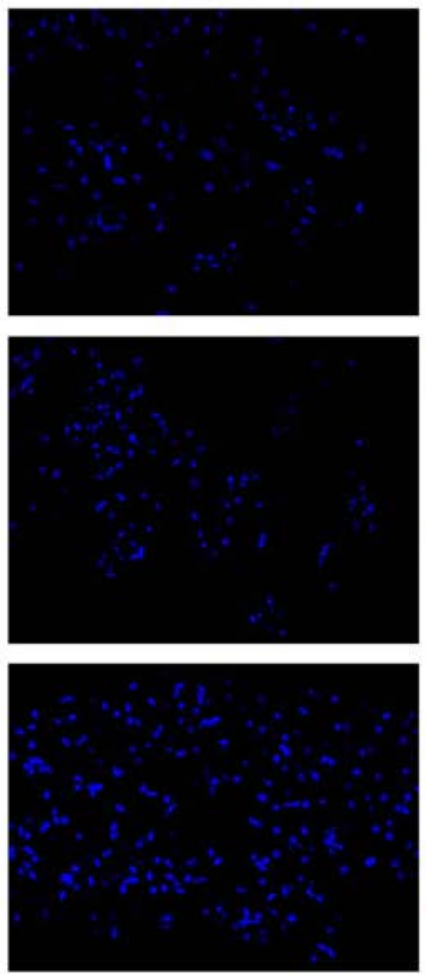

D

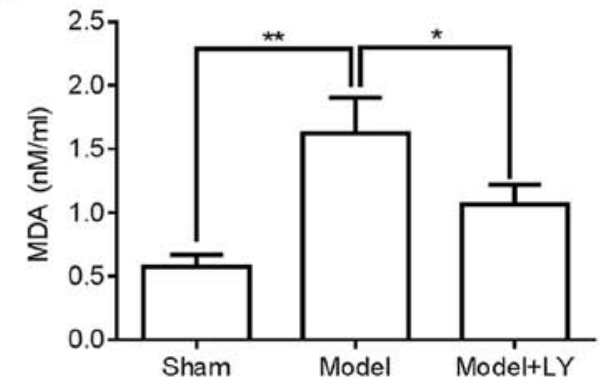

Figure 7. Effects of PI3K/AKT signaling on the thrombosis of femoral vein tissue of DVT. The activation of PI3K/AKT signaling was inhibited by pre-treatment with LY294002 $(50 \mathrm{mg} / \mathrm{kg})$. (A) Thrombosis in the femoral vein tissue of different treatment groups $(\mathrm{n}=6$ mice in each group) was examined by H\&E staining (black arrows indicate the femoral vein tissue; red arrows indicate thrombosis). (B) Cell apoptosis of the femoral vein tissue in mice was examined by TUNEL assay. (C and D) SOD and MDA concentrations in the femoral vein tissue of mice were examined by ELISA. ${ }^{*} \mathrm{P}<0.05$ and ${ }^{* *} \mathrm{P}<0.01$. DVT, deep vein thrombosis; $\mathrm{H} \& \mathrm{E}$, hematoxylin and eosin; SOD, superoxide dismutase; MDA, malondialdehyde.

protein promoted DVT formation by upregulating the protein expression of the inflammatory cytokines, TNF- $\alpha$, IL- 6 and IL-8, via PI3K/AKT signaling.

Accumulating evidence has demonstrated that the imbalance of inflammatory cytokine expression was closely associated with DVT formation $(22,23)$. TNF- $\alpha$, IL- 6 and IL- 8 proteins are important pro-inflammatory cytokines. It has been reported that the upregulation of miRNA-9-5p can alleviate thrombosis in rats with DVT by decreasing the expression of TNF- $\alpha$, IL-6 and IL-8 (24). Zhang et al demonstrated that anti-IL-6 antibody decreased IL-6 expression and alleviated DVT formation in a mouse model (7). The present study found that the levels of TNF- $\alpha$, IL-6 and IL-8 protein were significantly upregulated in the femoral vein tissue and plasma of mice with DVT compared with the control or sham groups, which is consistent with the findings of previous studies $(7,24)$. 
A

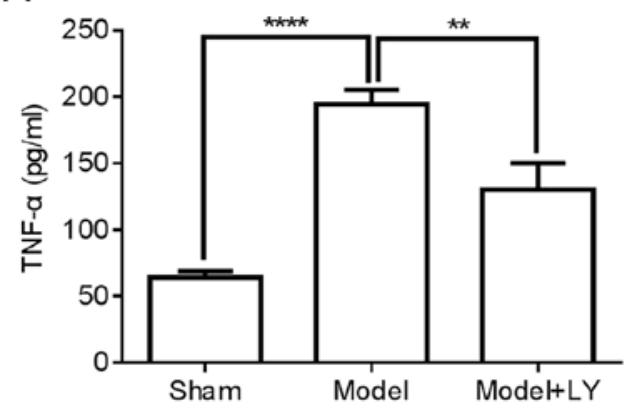

C

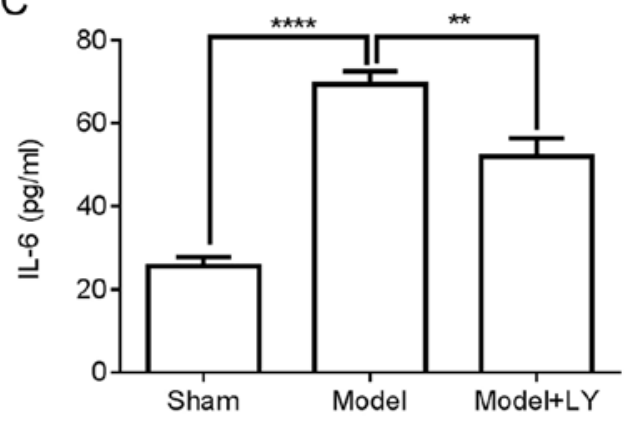

E

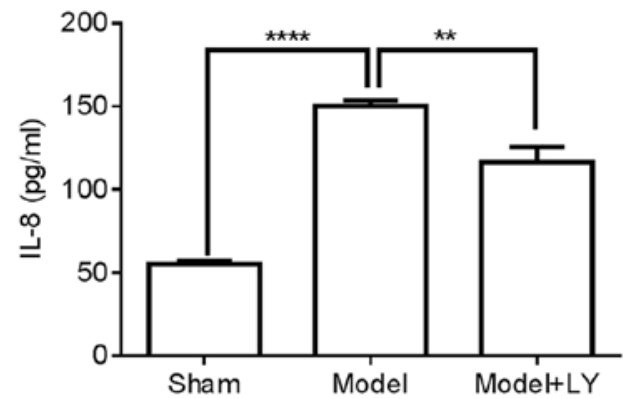

B

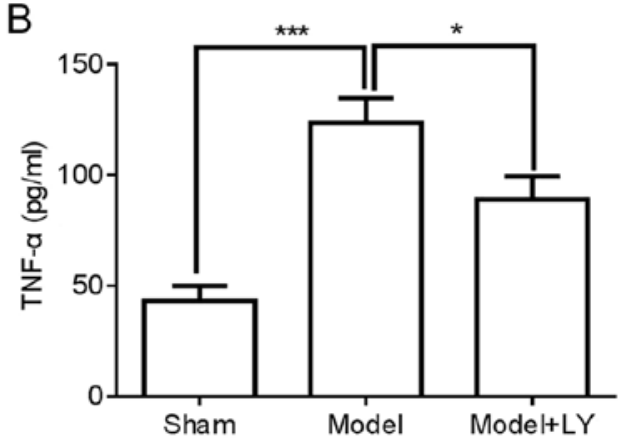

D

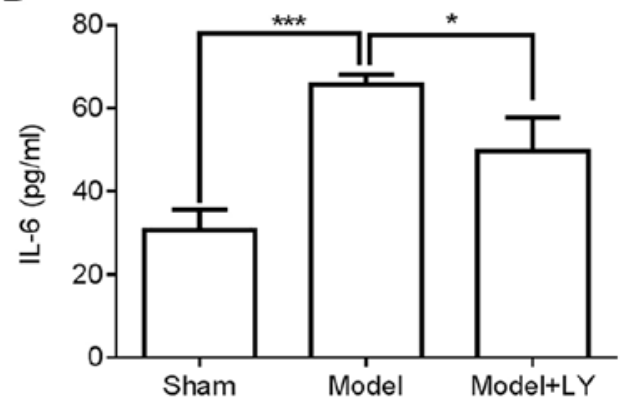

F

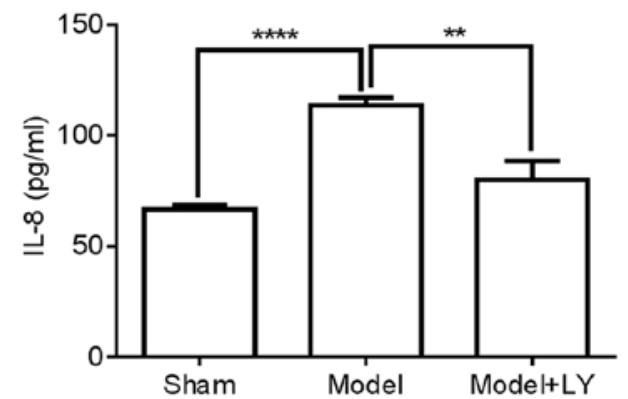

Figure 8. Effects of PI3K/AKT signaling on TNF- $\alpha$, IL-6 and IL-8 protein in the femoral vein tissue and plasma of DVT mice. The activation of PI3K/AKT signaling was inhibited by pretreatment with LY294002 $(50 \mathrm{mg} / \mathrm{kg})$. (A, C and E) The levels of TNF- $\alpha$, IL-6 and IL-8 in the femoral vein tissue of different treatment groups ( $\mathrm{n}=6$ mice in each group) were detected by ELISA. (B, D, and F) The levels of TNF- $\alpha$, IL- 6 and IL- 8 in the plasma of different treatment groups ( $\mathrm{n}=6$ mice in each group) were detected using ELISA. ${ }^{*} \mathrm{P}<0.05,{ }^{* *} \mathrm{P}<0.01,{ }^{* * *} \mathrm{P}<0.001$ and ${ }^{* * * *} \mathrm{P}<0.0001$. DVT, deep vein thrombosis.

These data further illustrated that the inflammatory cytokines, TNF- $\alpha$, IL-6 and IL-8, play a role in DVT formation.

Numerous studies have indicated that the PI3K/AKT signaling pathway is an important intracellular signaling pathway that plays a role in a variety of cellular physiological processes, including cell proliferation, cell apoptosis and inflammatory response (25-27). Chang et al reported that 7-ketocholesterol contributed to thrombosis via the induction of endothelial damage, apoptosis and inflammatory responses, which were associated with the activation of PI3K/AKT signaling (28). Su et al also reported that the pyrrolidinoindoline alkaloid, Psm2, alleviated platelet aggregation and thrombus formation by inhibiting PI3K/AKT signaling (29). Additionally, it has been reported that plantamajoside inhibited the lipopolysaccharide (LPS)-induced expression of IL- 6 and IL-8 by inhibiting PI3K/AKT signaling in human gingival fibroblasts (30). Vitamin D has been shown to attenuate the LPS-induced upregulation of TNF- $\alpha$ and IL- 6 by inhibiting PI3K/AKT signaling in human umbilical vein endothelial cells (31). The results of the present study suggested that PI3K/AKT signaling was activated in the femoral vein tissue of mice with DVT. Furthermore, LY294002 pre-treatment markedly decreased thrombosis and femoral vein tissue damage in mice with DVT. LY294002 pre-treatment also significantly attenuated the protein expression TNF- $\alpha$, IL- 6 and IL- 8 in the femoral vein tissue and plasma of mice with DVT. The results presented herein indicated that PI3K/AKT signaling induced DVT formation by inducing the inflammatory response.

FXII protein is an important member of the coagulation pathway and plays a key role in coagulation, fibrinolysis and angiogenesis. Increasing evidence has demonstrated that FXII protein is involved in regulating thrombosis $(12,32)$. Trauma-induced microvascular thrombus formation could be minimized by the inhibition of activated FXII in mice (33). The results of the present study also demonstrated that FXII protein expression was significantly increased in the femoral vein tissue of DVT mice compared with control or sham groups. The knockdown of FXII protein significantly attenuated thrombosis and femoral vein tissue damage in mice with 
DVT. Furthermore, LaRusch et al demonstrated that FXII induced the activation of AKT signaling in human umbilical vein endothelial cells (17). The data of the present study demonstrated that the knockdown of FXII protein significantly downregulated the activation of PI3K/AKT signaling in the femoral vein tissue of mice with DVT. Additionally, it has been demonstrated that the accumulation of FXII can induce the production and release of pro-inflammatory TNF- $\alpha$, IL- 6 and IL-8 proteins in lungs affected by acute respiratory distress syndrome (16). The present study also found that FXII protein knockdown significantly downregulated the protein expression TNF- $\alpha$, IL- 6 and IL- 8 in the femoral vein tissue and plasma of mice with DVT. These results suggested that FXII protein may induce DVT formation by activating PI3K/AKT signaling and promoting the inflammatory response. However, the present study did not examine the expression of other coagulation factors (XI, IX, VIII, VII and others) following the knockdown of FXII. The authors aim to clarify the effects of FXII on the expression of other coagulation factors in the future.

Taken together, the present study demonstrated that the upregulation of FXII protein may contribute to the formation of DVT in mice. The results further demonstrated that FXII protein promoted DVT formation by inducing the inflammatory response through the activation of PI3K/AKT signaling in mice with DVT. Therefore, the inhibition of FXII protein may be a potential strategy for the treatment of DVT.

\section{Acknowledgements}

Not applicable.

\section{Funding}

No funding was received.

\section{Availability of data and materials}

The datasets used and/or analyzed during the present study are available from the corresponding author on reasonable request.

\section{Authors' contributions}

YM and HT conducted the experiments and analyzed the data. YM, QY, QM and HT made substantial contributions to the design of the present study, and prepared the manuscript. HQ, BZ, HP and JZ performed the western blot analysis and analyzed the data. All authors read and approved the final manuscript.

\section{Ethics approval and consent to participate}

The experimental procedures and protocols were reviewed and approved by the Animal Investigation Ethics Committee of the First Affiliated Hospital of Xi'an Jiaotong University and were performed in accordance with the Guidelines for the Care and Use of Laboratory Animals from the National Institutes of Health, China.

\section{Patient consent for publication}

Not applicable.

\section{Competing interests}

The authors declare that they have no competing interests.

\section{References}

1. Strijkers RH, Cate-Hoek AJ, Bukkems SF and Wittens CH: Management of deep vein thrombosis and prevention of post-thrombotic syndrome. BMJ 343: d5916, 2011.

2. Sun J, Zhang Z, Ma T, Yang Z, Zhang J, Liu X, Lu D, Shen Z, Yang $J$ and Meng Q: Endothelial progenitor cell-derived exosomes, loaded with miR-126, promoted deep vein thrombosis resolution and recanalization. Stem Cell Res Ther 9: 223, 2018.

3. Giordano NJ, Jansson PS, Young MN, Hagan KA and Kabrhel C: Epidemiology, pathophysiology, stratification, and natural history of pulmonary embolism. Tech Vasc Interv Radiol 20: 135-140, 2017.

4. Appelen D, van Loo E, Prins MH, Neumann MH and Kolbach DN: Compression therapy for prevention of post-thrombotic syndrome. Cochrane Database Syst Rev 9: CD004174, 2017.

5. Yan Y, Yang H, Hu X, Zhang Z, Ge S, Xu Z, Gao J, Liu J, White GC and Ma YQ: Kindlin-3 in platelets and myeloid cells differentially regulates deep vein thrombosis in mice. Aging (Albany NY) 11: 6951-6959, 2019.

6. Sato K, Sakamoto K, Hashimoto Y, Hanzawa K, Sueta D, Kojima S, Fukuda M, Usuku H, Kihara F, Hosokawa H, et al: Risk factors and prevalence of deep vein thrombosis after the 2016 kumamoto earthquakes. Circ J 83: 1342-1348, 2019.

7. Zhang Y, Zhang Z, Wei R, Miao X, Sun S, Liang G, Chu C, Zhao L, Zhu X, Guo Q, et al: IL (Interleukin)-6 contributes to deep vein thrombosis and is negatively regulated by miR-338-5p. Arterioscler Thromb Vasc Biol 40: 323-334, 2020.

8. Jia Z, Tu J, Zhao J, Ren B, Tian F, Wang K, Li S and Jiang G: Aspiration thrombectomy using a large-size catheter for acute lower extremity deep vein thrombosis. J Vasc Surg Venous Lymphat Disord 4: 167-171, 2016.

9. Branchford BR and Carpenter SL: The role of inflammation in venous thromboembolism. Front Pediatr 6: 142, 2018.

10. van Montfoort ML and Meijers JC: Recent insights into the role of the contact pathway in thrombo-inflammatory disorders. Hematology Am Soc Hematol Educ Program 2014: 60-65, 2014.

11. Schmaier AH: Physiologic activities of the contact activation system. Thromb Res 133 (Suppl 1): S41-S44, 2014.

12. Zamolodchikov D, Renne T and Strickland S: The Alzheimer's disease peptide beta-amyloid promotes thrombin generation through activation of coagulation factor XII. J Thromb Haemost 14: 995-1007, 2016.

13. Renne T, Pozgajova M, Gruner S, Schuh K, Pauer HU, Burfeind P, Gailani D and Nieswandt B: Defective thrombus formation in mice lacking coagulation factor XII. J Exp Med 202: 271-281, 2005.

14. Kleinschnitz C, Stoll G, Bendszus M, Schuh K, Pauer HU, Burfeind P, Renné C, Gailani D, Nieswandt B and Renné T: Targeting coagulation factor XII provides protection from pathological thrombosis in cerebral ischemia without interfering with hemostasis. J Exp Med 203: 513-518, 2006.

15. Matafonov A, Leung PY, Gailani AE, Grach SL, Puy C, Cheng Q, Sun MF, McCarty OJ, Tucker EI, Kataoka H, et al: Factor XII inhibition reduces thrombus formation in a primate thrombosis model. Blood 123: 1739-1746, 2014.

16. Hess R, Wujak L, Hesse C, Sewald K, Jonigk D, Warnecke G, Fieguth HG, de Maat S, Maas C, Bonella F, et al: Coagulation factor XII regulates inflammatory responses in human lungs. Thromb Haemost 117: 1896-1907, 2017.

17. LaRusch GA, Mahdi F, Shariat-Madar Z, Adams G, Sitrin RG, Zhang WM, McCrae KR and Schmaier AH: Factor XII stimulates ERK1/2 and Akt through uPAR, integrins, and the EGFR to initiate angiogenesis. Blood 115: 5111-5120, 2010.

18. Schonfelder T, Jackel S and Wenzel P: Mouse models of deep vein thrombosis. Gefasschirurgie 22: 28-33, 2017.

19. Tokgoz VY, Sipahi M, Keskin O, Guvendi GF and Takir S: Protective effects of vitamin D on ischemia-reperfusion injury of the ovary in a rat model. Iran J Basic Med Sci 21: 593-599, 2018.

20. Xu L, Yu Y, Sang R, Li J, Ge B and Zhang X: Protective effects of Taraxasterol against Ethanol-Induced liver injury by regulating CYP2E1/Nrf2/HO-1 and NF- $\kappa \mathrm{B}$ signaling pathways in mice. Oxid Med Cell Longev 2018: 8284107, 2018.

21. Lu Y, Wu S, Xiang B, Li L and Lin Y: Curcumin attenuates oxaliplatin-induced liver injury and oxidative stress by activating the Nrf2 pathway. Drug Des Devel Ther 14: 73-85, 2020. 
22. Roumen-Klappe EM, den Heijer M, van Uum SH van der Ven-Jongekrijg J, van der Graaf $F$ and Wollersheim $H$ : Inflammatory response in the acute phase of deep vein thrombosis. J Vasc Surg 35: 701-706, 2002.

23. Tato F: Deep vein thrombosis-advances in diagnosis and treatment. MMW Fortschr Med: 156 Spec no 2: 59-63; quiz 64, 2014 (In German).

24. Ou M, Zhang Y, Cui S, Zhao S and Tu J: Upregulated MiR-9-5p protects against inflammatory response in rats with deep vein thrombosis via inhibition of NF- $\mathrm{B}$ p 50 . Inflammation 42 : 1925-1938, 2019

25. Li Y, Jiang Y, Wan Y, Zhang L, Tang W, Ma J, Wu S and Cheng W: Medroxyprogestogen enhances apoptosis of SKOV-3 cells via inhibition of the PI3K/Akt signaling pathway. J Biomed Res 27: 43-50, 2013.

26. Involvement of pro-inflammatory cytokines in diabetic neuropathic pain via central PI3K/Akt/mTOR signal pathway. Arch Physiol Biochem: Dec 11, 2019 (Epub ahead of print). doi: 10.10 80/13813455.2019.1700048.

27. Zhang HB, Tu XK, Chen Q and Shi SS: Propofol reduces inflammatory brain injury after subarachnoid hemorrhage: Involvement of PI3K/Akt pathway. J Stroke Cerebrovasc Dis 28: 104375, 2019.

28. Chang MC, Chen YJ, Liou EJ, Tseng WY, Chan CP, Lin HJ, Liao WC, Chang YC, Jeng PY and Jeng JH: 7-Ketocholesterol induces ATM/ATR, Chk1/Chk2, PI3K/Akt signalings, cytotoxicity and IL-8 production in endothelial cells. Oncotarget 7: 74473-74483, 2016.
29. Su XL, Su W, Wang Y, Wang YH, Ming X and Kong Y: The pyrrolidinoindoline alkaloid Psm2 inhibits platelet aggregation and thrombus formation by affecting PI3K/Akt signaling. Acta Pharmacol Sin 37: 1208-1217, 2016.

30. Liu F, Huang X, He JJ, Song C, Peng L, Chen T and Wu BL: Plantamajoside attenuatesinflammatory response in LPS-stimulated human gingival fibroblasts by inhibiting PI3K/AKT signaling pathway. Microb Pathog 127: 208-211, 2019.

31. Zhou W, Yuan G and Wang Q: Vitamin D attenuates lipopolysaccharide-induced inflammatory response in endothelial cells through inhibition of PI3K/Akt/NF- $\mathrm{B}$ signaling pathway. Pharmazie 74: 412-417, 2019.

32. Maas C and Renne T: Coagulation factor XII in thrombosis and inflammation. Blood 131: 1903-1909, 2018.

33. Hopp S, Albert-Weissenberger C, Mencl S, Bieber M, Schuhmann MK, Stetter C, Nieswandt B, Schmidt PM, Monoranu CM, Alafuzoff I, et al: Targeting coagulation factor XII as a novel therapeutic option in brain trauma. Ann Neurol 79: 970-982, 2016.

c) (i) $\ominus$ This work is licensed under a Creative Commons Attribution-NonCommercial-NoDerivatives 4.0 International (CC BY-NC-ND 4.0) License. 